\title{
CrystEngComm
}

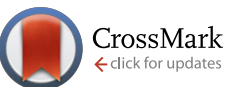

Cite this: CrystEngComm, 2017, 19, 1408

Received 8th November 2016, Accepted 4th February 2017

DOI: $10.1039 / c 6 c e 02340 a$

rsc.li/crystengcomm

\section{pH-regulated antimony oxychloride nanoparticle formation on titanium oxide nanostructures: a photocatalytically active heterojunction $\uparrow$}

\author{
Balázs Buchholcz, ${ }^{a}$ Henrik Haspel, +ł Tamás Boldizsár, ${ }^{a}$ \\ Ákos Kukovecz ${ }^{\mathrm{ab}}$ and Zoltán Kónya*ac
}

\begin{abstract}
Improving the catalytic activity of heterogeneous photocatalysts has become a hot topic recently. To this end, considerable progress has been made in the efficient separation of photogenerated charge carriers by e.g. the realization of heterojunction photocatalysts. V-VI-VII compound semiconductors, namely, bismuth oxyhalides, are popular photocatalysts. However, results on antimony oxyhalides $\left[\mathrm{Sb}_{x} \mathrm{O}_{y} \mathrm{X}_{z}(\mathrm{X}=\mathrm{Br}, \mathrm{Cl}, \mathrm{I})\right]$, the very promising alternatives to the well-known $\mathrm{Bi}_{x} \mathrm{O}_{y} \mathrm{X}_{z}$ photomodifiers, are scarce. Here, we report the successful decoration of titanium oxide nanostructures with 8-11 nm diameter $\mathrm{Sb}_{x} \mathrm{O}_{y} \mathrm{X}_{z}$ nanoparticles for the first time ever. The product size and stoichiometry could be controlled by the $\mathrm{pH}$ of the reactant mixture, while subsequent calcination could transform the structure of the titanate nanotube (TiONT) support and the prepared antimony oxychloride particles. In contrast to the ease of composite formation in the $\mathrm{Sb}_{x} \mathrm{O}_{y} \mathrm{X}_{z} / \mathrm{TiONT}$ case, anatase $\mathrm{TiO}_{2}$ could not facilitate the formation of antimony oxychloride nanoparticles on its surface. The titanate nanotube-based composites showed activity in a generally accepted quasistandard photocatalytic test reaction (methyl orange dye decolorization). We found that the $\mathrm{Sb}_{x} \mathrm{O}_{y} \mathrm{Cl}_{z} /$ TiONT synthesized at $\mathrm{pH}=1$ is the most active sample in a broad temperature range.
\end{abstract}

\section{Introduction}

In photocatalysis, redox reactions are initiated by incident UV, ${ }^{1}$ UV-vis, ${ }^{2}$ visible, ${ }^{3}$ or $\mathrm{NIR}^{4}$ irradiation, and are promoted by the presence of a solid catalyst particle. Since only $6 \%$ of the solar radiation energy falls into the UV range, while half of the total energy arrives in the visible region at the sea level, efficient harvesting of the sun's energy is of great importance. It was recognized early on that fast charge carrier recombination limits the activity of a photocatalyst due to the short lifetime of the electron-hole pairs. One solution to overcome this issue is the construction of semiconductor heterojunctions that can facilitate charge carrier redistribution via an internal electric field at the interface. To

\footnotetext{
${ }^{a}$ Department of Applied and Environmental Chemistry, University of Szeged, Rerrich Béla tér 1, H-6720 Szeged, Hungary.E-mail: konya@chem.u-szeged.hu; Fax: +36 62544 619; Tel: +36 62544620

${ }^{b}$ MTA-SZTE "Lendület" Porous Nanocomposites Research Group, Rerrich Béla tér 1, H-6720 Szeged, Hungary

${ }^{c}$ MTA-SZTE Reaction Kinetics and Surface Chemistry Research Group, Rerrich Béla tér 1, H-6720 Szeged, Hungary

$\dagger$ Electronic supplementary information (ESI) available. See DOI: 10.1039/ c6ce02340a

\$ Present address: King Abdullah University of Science and Technology (KAUST), KAUST Catalysis Center (KCC), and Physical Sciences and Engineering Division (PSE), Thuwal, 23955-6900, Saudi Arabia.
}

this end, promotion of photoinduced charge carrier generation and subsequent electron-hole separation by e.g. semiconductor-semiconductor composite structures is a promising way to go. ${ }^{5,6}$

Multicomponent V-VI-VII semiconductors, such as bismuth oxyhalides $\left(\mathrm{Bi}_{x} \mathrm{O}_{y} \mathrm{X}_{z}\right)$, are a family of photocatalytically active materials utilizing $\mathrm{UV}^{7}$ or visible-light irradiation. ${ }^{8,9} \mathrm{Al}$ though the catalytic activity of $\mathrm{Bi}_{x} \mathrm{O}_{y} \mathrm{X}_{z}$ compounds ${ }^{10}$ and their composites ${ }^{11}$ is well-known from the literature, $\mathrm{Sb}_{x} \mathrm{O}_{y} \mathrm{Cl}_{z}$ structures are mostly used as flame retardants ${ }^{12}$ and coloring additives in plastics. ${ }^{13}$ Recently, $\mathrm{PbSbO}_{2} \mathrm{Cl}$ (ref. 14) and $\mathrm{PbCl}_{2} / \mathrm{Sb}_{4} \mathrm{O}_{5} \mathrm{Cl}_{2}$ (ref. 15) were suggested as promising, high capacity anode materials for lithium ion batteries. Members of the antimony oxyhalide family $\left[\mathrm{Sb}_{x} \mathrm{O}_{y} \mathrm{X}_{z}(\mathrm{X}=\mathrm{Br}, \mathrm{Cl}, \mathrm{I})\right]$ went largely unnoticed as possible photocatalysts until now. Studies on photocatalytic $\mathrm{Sb}_{x} \mathrm{O}_{y} \mathrm{Cl}_{z}$ structures $\left(\mathrm{Sb}_{4} \mathrm{O}_{5} \mathrm{Cl}_{2}\right)$ have been initiated very recently, ${ }^{16}$ and to the best of our knowledge, only $\mathrm{Sb}_{2} \mathrm{~S}_{3} / \mathrm{Sb}_{4} \mathrm{O}_{5} \mathrm{Cl}_{2}$ (ref. 17) and $\mathrm{g}-\mathrm{C}_{3} \mathrm{~N}_{4}-\mathrm{Sb}_{2} \mathrm{~S}_{3} / \mathrm{Sb}_{4} \mathrm{O}_{5} \mathrm{Cl}_{2}$ (ref. 18) semiconductor-semiconductor heterostructures were constructed so far. Furthermore, although antimony oxychlorides were successfully synthesized with different stoichiometries (like $\mathrm{Sb}_{4} \mathrm{O}_{5} \mathrm{Cl}_{2}, \mathrm{Sb}_{8} \mathrm{O}_{11} \mathrm{Cl}_{2}$, and the trivalent oxide $\mathrm{Sb}_{2} \mathrm{O}_{3}$ (ref. 19 and 20)) and in various morphologies in the past (microspheres, ${ }^{16}$ nanorods, nanowires ${ }^{20}$ etc.), the synthesis of supported $\mathrm{Sb}_{x} \mathrm{O}_{y} \mathrm{Cl}_{z}$ nanoparticles has not been reported yet. 
Titanate nanotubes are layered $\mathrm{Na}^{+}$- or $\mathrm{H}^{+}$-trititanates $\left[\left(\mathrm{H}_{x}\right.\right.$, $\left.\left.\mathrm{Na}_{2-x}\right) \mathrm{Ti}_{3} \mathrm{O}_{7}\right]$ featuring a tubular morphology and relatively large specific surface area and pore volume: $170-250 \mathrm{~m}^{2} \mathrm{~g}^{-1}$ and $0.5-0.8 \mathrm{~cm}^{3} \mathrm{~g}^{-1}$, respectively. ${ }^{21}$ Layered trititanates are easily ion-exchangeable, ${ }^{22}$ are able to immobilize nanoparticles on their surface ${ }^{23}$ and can be doped easily by e.g. nitrogen. ${ }^{24}$ The stability of trititanates depends on (i) the exchanged interlayer ions, (ii) the nanoparticles decorating their surface and (iii) the doping elements built into their structure. $^{23,24}$ Moreover, a proton-exchanged multiwalled trititanate nanostructure can be transformed into high surface area tubular anatase $\mathrm{TiO}_{2},{ }^{21}$ too.

Here we report the successful fabrication of a Type II (staggered) $\mathrm{n}-\mathrm{n}$ heterojunction between antimony oxychloride/antimony oxide nanoparticles and different titanium oxide phases. As-prepared and annealed titanate nanotubes and anatase $\mathrm{TiO}_{2}$ were considered as potential catalyst supports in this study. The photocatalytic activity of the composites was characterized in organic dye decolorization tests using methyl orange as the substrate. Although studies on bismuth oxyhalide decorated $\mathrm{TiO}_{2}$ structures, like BiOX $(\mathrm{Cl}$, $\mathrm{Br}, \mathrm{I})$ and $\mathrm{BiOCl}$ nanoparticles on anatase $\mathrm{e}^{25,26}$ and rutile, ${ }^{27}$ or both $^{28} \mathrm{BiOCl}$ on mesoporous ${ }^{29}$ and bismuth-doped $\mathrm{TiO}_{2}{ }^{30}$ BiOCl and BiOI on $\mathrm{TiO}_{2}$ nanofibers, ${ }^{31,32}$ can be found in the literature, $\mathrm{Sb}_{x} \mathrm{O}_{y} \mathrm{Cl}_{z}$ nanoparticle decorated nanostructures and their photocatalytic activity are described here for the first time.

\section{Experimental}

\subsection{Synthesis of titanate nanotubes}

Titanate nanotubes were prepared via a hydrothermal route. ${ }^{33}$ In a typical synthesis, $50 \mathrm{~g}$ of titanium(Iv) oxide powder (99.8\% anatase, Sigma-Aldrich) and $1 \mathrm{~L} 10 \mathrm{M}$ aqueous $\mathrm{NaOH}$ solution (99.93\%, Molar) were mixed for 1 hour. The obtained white suspension was transferred into a PTFE-lined stainless steel autoclave (diameter $120 \mathrm{~mm}$, height $250 \mathrm{~mm}$ ) and kept at $130{ }^{\circ} \mathrm{C}$ for 24 hours while rotating the autoclave continuously at $3 \mathrm{rpm}$ around its short axis. The white precipitate was washed with $0.01 \mathrm{M}$ aqueous $\mathrm{HCl}$ solution (Molar) to neutral $\mathrm{pH}$ and finally, the remaining $\mathrm{NaCl}$ was washed out with deionized water. The resulting titanate nanotubes were dried in air at $60{ }^{\circ} \mathrm{C}$ for 48 hours.

Since the $\mathrm{Na}^{+}$content of layered trititanates affects their phase transformations, $\mathrm{Na}^{+}$was replaced by $\mathrm{H}^{+}$by a one week long acidic washing using $0.01 \mathrm{~mol} \mathrm{dm}^{-3}$ aqueous $\mathrm{HCl}$ solution. The remaining $\mathrm{NaCl}$ was washed out of the system with deionized water. The obtained sample consisted of protonexchanged titanate nanotubes (described with the approximate formula $\mathrm{H}_{x} \mathrm{Na}_{2-x} \mathrm{Ti}_{3} \mathrm{O}_{7}$, where $x>1.98$ ). It was dried at $60{ }^{\circ} \mathrm{C}$ for 2 days, labelled "TiONT" and used in all subsequent experiments in this form.

\subsection{Preparation of the photocatalysts}

Three different types of SbOCl nanoparticles were synthesized directly on the support surface via a solvothermal route, as reported by Chen et al., ${ }^{20}$ The stoichiometry of the antimony oxychloride samples was controlled by the $\mathrm{pH}$ of the synthesis medium. $\operatorname{SbCl}_{3}(\geq 99 \%$, Sigma-Aldrich) was added to $0.28 \mathrm{dm}^{3}$ of a vigorously stirred $50 / 50 \mathrm{v} / \mathrm{v} \%$ mixture of ethylene glycol and ion-exchanged water before the as-prepared TiONTs were added to the suspension. The $\mathrm{pH}$ of the medium was 1-2 at this step, while $\mathrm{pH}=4-5$ and $\mathrm{pH}=8-9$ samples were prepared by adding the necessary amount of $6 \mathrm{~mol}$ $\mathrm{dm}^{-3} \mathrm{NaOH}$ solution. These three samples were labeled " $\mathrm{pH}$ 1", "pH 4" and "pH 8", respectively. After 1 hour of intensive stirring, the suspension was transferred into a $0.4 \mathrm{dm}^{3}$ PTFElined stainless steel autoclave and kept at $120{ }^{\circ} \mathrm{C}$ for 12 hours. The overall antimony content was $15 \mathrm{wt} \%$ for all composites. The pale yellowish product was washed with deionized water to remove chloride ions and dried at $60{ }^{\circ} \mathrm{C}$ for 24 hours. The pristine and nanoparticle decorated samples were subjected to thermal annealing at 100, 200, 300 and $400{ }^{\circ} \mathrm{C}$ for $1 \mathrm{~h}$. The product materials were characterized after each annealing step. Commercial anatase $\mathrm{TiO}_{2}$ was decorated and heat treated by following exactly the same protocol and used as the reference material.

\subsection{Characterization methods}

The morphology of the samples was studied using a FEI Tecnai $\mathrm{G}^{2} 20 \mathrm{X}$-Twin transmission electron microscope (TEM) operated at $200 \mathrm{kV}$. Elemental analysis was carried out using a Röntec QX2 energy dispersive X-ray spectrometer mounted in a Hitachi S-4700 Type II FE-SEM instrument. The band gaps of the as-prepared TiONT and the composites were determined using an Ocean Optics USB4000 UV-vis spectrometer with a DH-2000-BAL UV-vis-NIR light source and a diffuse reflectance probe. The crystallinity of the structures was investigated by means of a Rigaku Miniflex II X-ray diffractometer (XRD) using a $\mathrm{Cu} \mathrm{K} \alpha \mathrm{X}$-ray source $(\lambda=0.1542 \mathrm{~nm})$ at 30 $\mathrm{kV}$ and $15 \mathrm{~mA}$. Diffractograms were recorded in the $10-70^{\circ}$ $2 \Theta$ range at a $4^{\circ} \mathrm{min}^{-1} \mathrm{scan}$ rate. The flat band potential of the $\mathrm{pH} 1$ sample was determined in $0.5 \mathrm{M} \mathrm{Na}_{2} \mathrm{SO}_{4}$ solution in a three-electrode configuration using an ACM Instruments Gill AC electrochemical workstation, as described in the $\mathrm{ESI}^{\dagger}$ in more detail.

\subsection{Photocatalytic experiments}

The photocatalytic activity of the pristine and heat-treated TiONTs and $\mathrm{Sb}_{x} \mathrm{O}_{y} \mathrm{Cl}_{z} / \mathrm{TiONT}$ composites was tested by methyl orange (MO) degradation under UV/vis irradiation using a 40 W Medicor Q 250 mercury vapor lamp. The reaction took place at $25^{\circ} \mathrm{C}$ in a batch reactor thermostated using a Julabo F12 thermostat. The spectrum of the light source is depicted in Fig. S1. $\dagger$ In each experiment, a $10 \mathrm{mg}$ sample was continuously stirred in $10 \mathrm{mg} \mathrm{l}^{-1}$ aqueous methyl orange solution and irradiated for 5, 10 and 15 minutes. Before every measurement, the solution was stirred in the dark for one hour to reach the adsorption-desorption equilibrium. The change in methyl orange concentration was monitored at the 
wavelength of maximum absorption of the solution $(\lambda=464$ nm) using a Hitachi U-2001 UV-vis spectrophotometer.

\section{Results and discussion}

\subsection{Morphology of the photocatalysts}

The morphology of the as-prepared titanate nanotubes and the composites can be seen in the TEM images in Fig. 1. The elongated, open-ended trititanate structures had 5-6 nm inner and 10-11 $\mathrm{nm}$ outer diameters; the separation between nanotube walls was $0.79 \mathrm{~nm}$. The average length of the tubes was between 100 and $300 \mathrm{~nm}$. Since the success of the $\mathrm{Sb}_{x} \mathrm{O}_{y} \mathrm{Cl}_{z}$ decoration cannot be unambiguously confirmed solely via TEM investigations, the presence of antimony in all samples was confirmed using EDS. The relevant energy dispersive X-ray spectra are shown in Fig. S2. $\dagger$ The emission lines at 3.189, 3.600, 3.844, and $4.101 \mathrm{keV}$ are characteristic of the $\mathrm{LI}, \mathrm{L} \alpha, \mathrm{L} \beta_{1}$, and $\mathrm{L} \beta_{2}$ antimony X-ray lines, while the $\mathrm{L} \gamma_{1}$ line at $4.348 \mathrm{keV}$ is masked by the intensive $\mathrm{K} \alpha$ emission of titanium at $4.508 \mathrm{keV}$.

It can be seen in Fig. $1 \mathrm{a} 2$ and a3 that $\mathrm{Sb}_{x} \mathrm{O}_{y} \mathrm{Cl}_{z}$ nanoparticles were successfully synthesized on the titanate surface with average diameters of $7.8 \pm 1.7,10.4 \pm 2.3$, and $11.4 \pm 2.8$ $\mathrm{nm}$ at $\mathrm{pH}=1$ (Fig. 1a2), $\mathrm{pH}=4$ (Fig. 1a3), and $\mathrm{pH}=8$ (Fig. 1a4), respectively. These sizes are comparable with the outer diameter of the support. The solvothermal synthesis did not destroy the tubular morphology. As nanoparticles form bridges between adjacent nanotubes, a quasicontinuous heterojunction network emerges. Interestingly, nanoparticles were not formed under the same synthesis conditions when anatase $\mathrm{TiO}_{2}$ was used as the support, as clearly demonstrated in Fig. S3.† The 70-150 nm large anatase grains are unevenly covered by irregularly shaped $\mathrm{Sb}_{x} \mathrm{O}_{y} \mathrm{Cl}_{z}$ clusters measuring tens of nanometers in diameter. The presence of $\mathrm{Sb}_{x} \mathrm{O}_{y} \mathrm{Cl}_{z} / \mathrm{TiONT}$ heterojunctions is clearly seen in Fig. b1-3 in the case of $\mathrm{pH}=1, \mathrm{pH}=4, \mathrm{pH}=8$, respectively. The interplanar spacing value was $\sim 0.36 \mathrm{~nm}$ for the $\mathrm{Sb}_{x} \mathrm{O}_{y} \mathrm{Cl}_{z}$ nanoparticles at $\mathrm{pH}=1$ and $\mathrm{pH}=4$, which corresponds to the $\mathrm{Sb}_{4} \mathrm{O}_{5} \mathrm{Cl}_{2}$ and $\mathrm{Sb}_{8} \mathrm{O}_{11} \mathrm{Cl}_{2}$ (111) lattice planes. At $\mathrm{pH}=8$, the $\mathrm{d}$ spacing value was $0.349 \mathrm{~nm}$, which matches the (111) lattice plane of orthorhombic $\mathrm{Sb}_{2} \mathrm{O}_{3}$ well.

It is widely known that the structure and morphology of TiONTs change during heat treatment. The wall structure of the protonated trititanate tube collapses at $400{ }^{\circ} \mathrm{C}$, and the material transforms into anatase tubes or wires. ${ }^{32,33}$ At elevated temperatures, anatase nanotubes convert first into anatase nanorods, then at higher temperature into mixed phase rutile/anatase nanorods. ${ }^{21,24}$ Nanoparticles decorating the TiONT surface and ions in ion exchange positions also influence the transformation temperature and the resulting structure. The effect of $400{ }^{\circ} \mathrm{C}$ calcination on the $\mathrm{Sb}_{x} \mathrm{O}_{y} \mathrm{Cl}_{z} / \mathrm{TiONT}$ composites is demonstrated in Fig. 2.

The pristine TiONT has lost its tubular morphology upon thermal treatment as 40-70 nm long nanorods were formed (Fig. 2a). The $\mathrm{Sb}_{x} \mathrm{O}_{y} \mathrm{Cl}_{z} /$ TiONT composite synthesized at $\mathrm{pH}=$ 1 (Fig. 2b) contains elongated rod-like fragments and more regularly shaped particles with a $\mathbf{1 0 - 1 5} \mathrm{nm}$ diameter as well. Samples prepared at $\mathrm{pH}=4$ and 8 exhibit even more diverse morphologies accompanied by a higher polydispersity (Fig. 2c and d).

In summary, the TEM investigation proved that it is possible to decorate TiONTs but not anatase $\mathrm{TiO}_{2}$ with

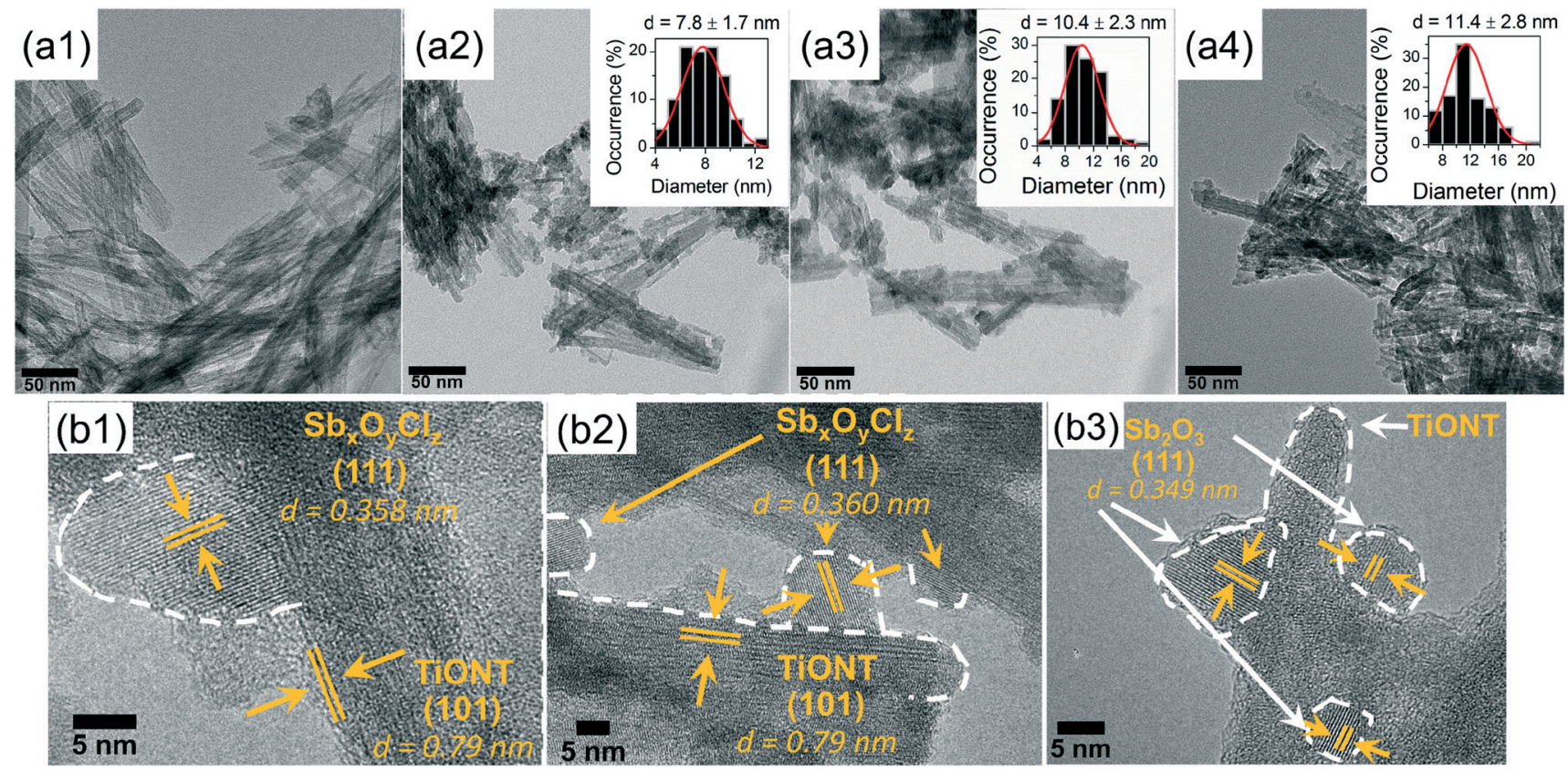

Fig. 1 TEM images of pristine titanate nanotubes (TiONT) (a1), and nanotubes decorated with $\mathrm{Sb}_{x} \mathrm{O}_{y} \mathrm{Cl}_{z}$ nanoparticles synthesized at pH = 1 (a2), $\mathrm{pH}=4(\mathrm{a} 3)$, and $\mathrm{pH}=8$ (a4). Inset graphs depict the corresponding particle size distributions, as determined from TEM images. HRTEM images of $\mathrm{Sb}_{x} \mathrm{O}_{y} \mathrm{Cl}_{z} / \mathrm{TiONT}$ heterojunctions are shown in (b1-3) for $\mathrm{pH}=1, \mathrm{pH}=4$ and $\mathrm{pH}=8$, respectively. 

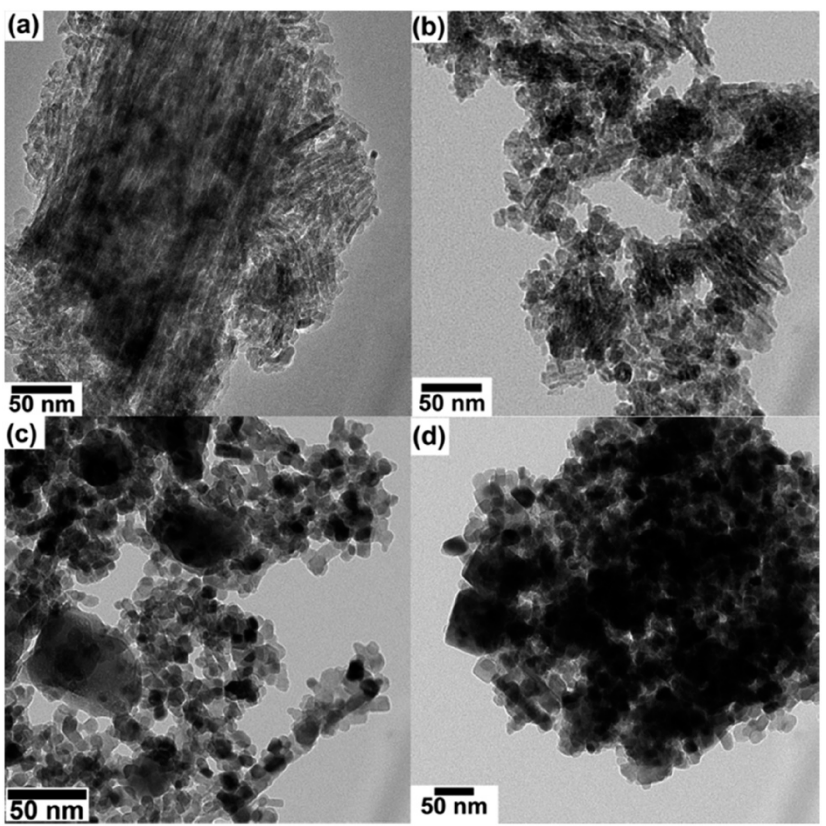

Fig. 2 TEM images demonstrating the effect of calcination at $400{ }^{\circ} \mathrm{C}$ on pristine titanate nanotubes (TiONT) (a), and on nanotubes decorated with $\mathrm{Sb}_{x} \mathrm{O}_{y} \mathrm{Cl}_{z}$ nanoparticles synthesized at $\mathrm{pH}=1$ (b), $\mathrm{pH}=$ 4 (c), and $\mathrm{pH}=8$ (d).

antimony oxychloride nanoparticles with diameters between 8 and $11 \mathrm{~nm}$. A possible reason behind the inferior performance of anatase $\mathrm{TiO}_{2}$ as a support material is that layered trititanates offer more possibilities for anchoring $\mathrm{SbO}^{+}$cations on their surface via Coulombic interaction. The presence of $\mathrm{Sb}_{x} \mathrm{O}_{y} \mathrm{Cl}_{z}$ particles and the $\mathrm{pH}$ of the synthesis medium affect the morphology of the calcined product (Fig. 2).

\subsection{Crystal phase of the photocatalysts}

Anatase $\mathrm{TiO}_{2}$ transforms into rutile at elevated $\left(700-1000{ }^{\circ} \mathrm{C}\right)$ temperatures. ${ }^{34}$ However, as mentioned above, protonated trititanates can be converted into anatase even under milder conditions, e.g. at around $400{ }^{\circ} \mathrm{C}$, when decorated with nanoparticles. ${ }^{21}$ These particles can promote either the preservation or, in contrast, the destruction of the original structure. ${ }^{23,35}$

The structures and stoichiometries of antimony oxides and oxychlorides are still under debate. Although the literature on antimony oxychloride is scarce, some reactions and products with different compositions and structures have been proposed already. It was reported that in the reaction of antimony chloride and water, $\mathrm{SbOCl}, \mathrm{Sb}_{4} \mathrm{O}_{5} \mathrm{Cl}_{2}$ and $\mathrm{Sb}_{2} \mathrm{O}_{3}$ can be formed according to the following equations: ${ }^{16}$

$$
\begin{gathered}
\mathrm{SbCl}_{3}+\mathrm{H}_{2} \mathrm{O} \rightarrow \mathrm{SbOCl}+2 \mathrm{HCl} \\
4 \mathrm{SbOCl}+\mathrm{H}_{2} \mathrm{O} \rightarrow \mathrm{Sb}_{4} \mathrm{O}_{5} \mathrm{Cl}_{2}+2 \mathrm{HCl} \\
\mathrm{NH}_{4} \mathrm{OH}+\mathrm{HCl} \rightarrow \mathrm{NH}_{4} \mathrm{Cl}+\mathrm{H}_{2} \mathrm{O}
\end{gathered}
$$

$$
\begin{gathered}
4 \mathrm{SbOCl}+2 \mathrm{NH}_{4} \mathrm{OH} \rightarrow \mathrm{Sb}_{2} \mathrm{O}_{3}+2 \mathrm{NH}_{4} \mathrm{Cl}+\mathrm{H}_{2} \mathrm{O} \\
\mathrm{Sb}_{4} \mathrm{O}_{5} \mathrm{Cl}_{2}+2 \mathrm{NH}_{4} \mathrm{OH} \rightarrow 2 \mathrm{Sb}_{2} \mathrm{O}_{3}+2 \mathrm{NH}_{4} \mathrm{Cl}+\mathrm{H}_{2} \mathrm{O}
\end{gathered}
$$

However, other authors reported different reaction pathways to describe the formation of $\mathrm{Sb}_{8} \mathrm{O}_{11} \mathrm{Cl}_{2}$ and $\mathrm{Sb}_{2} \mathrm{O}_{3}$ :

$8 \mathrm{SbCl}_{3}+17 \mathrm{H}_{2} \mathrm{O} \rightarrow \mathrm{Sb}_{8} \mathrm{O}_{11} \mathrm{Cl}_{2}\left(\mathrm{H}_{2} \mathrm{O}\right)_{6}+22 \mathrm{HCl}$ Room tempera-
ture [19]

$8 \mathrm{SbCl}_{3}+11 \mathrm{H}_{2} \mathrm{O} \rightarrow \mathrm{Sb}_{8} \mathrm{O}_{11} \mathrm{Cl}_{2}+22 \mathrm{HCl} 70^{\circ} \mathrm{C}$ in water bath or $180^{\circ} \mathrm{C}$ (hydrothermal) [19]

$\mathrm{Sb}_{8} \mathrm{O}_{11} \mathrm{Cl}_{2}+\mathrm{H}_{2} \mathrm{O} \rightarrow 4 \mathrm{Sb}_{2} \mathrm{O}_{3}+2 \mathrm{HCl} 70^{\circ} \mathrm{C}$ in water bath or $180{ }^{\circ} \mathrm{C}$ (hydrothermal) [19]

$$
2 \mathrm{SbCl}_{3}+3 \mathrm{OH}^{-} \rightarrow \mathrm{Sb}_{2} \mathrm{O}_{3}+3 \mathrm{HCl}+3 \mathrm{Cl}^{-}
$$

cubic senarmontite $\rightarrow$ orthorhombic valentinite High tem-

$$
\text { perature [19] }
$$

High temperature calcination could significantly alter the stoichiometry and/or the corresponding structure of antimony oxychloride products. The thermal behavior of the SbOCl, $\mathrm{Sb}_{4} \mathrm{O}_{5} \mathrm{Cl}_{2}$ and $\mathrm{Sb}_{2} \mathrm{O}_{3}$ product line was suggested to be described by the following non-stoichiometric transformations: ${ }^{36}$

$$
\begin{gathered}
192-296{ }^{\circ} \mathrm{C} \quad \mathrm{SbOCl}(\mathrm{s}) \rightarrow \mathrm{Sb}_{4} \mathrm{O}_{5} \mathrm{Cl}_{2}(\mathrm{~s})+\mathrm{Sb}_{2} \mathrm{O}_{3}(\mathrm{~g}) \\
425-521{ }^{\circ} \mathrm{C} \quad \mathrm{Sb}_{4} \mathrm{O}_{5} \mathrm{Cl}_{2}(\mathrm{~s}) \rightarrow \mathrm{Sb}_{8} \mathrm{O}_{11} \mathrm{Cl}_{2}(\mathrm{~s})+\mathrm{Sb}_{2} \mathrm{O}_{3}(\mathrm{~g}) \\
496-608{ }^{\circ} \mathrm{C} \quad \mathrm{Sb}_{8} \mathrm{O}_{11} \mathrm{Cl}_{2}(\mathrm{~s}) \rightarrow \mathrm{O}_{2}+\mathrm{Sb}_{2} \mathrm{O}_{4}(\mathrm{~g})
\end{gathered}
$$

The thermal transformation and decomposition of $\mathrm{Sb}_{8} \mathrm{O}_{11} \mathrm{Cl}_{2}$ was assumed according to these nonstoichiometric transformations: ${ }^{12}$

$$
\begin{gathered}
0-130{ }^{\circ} \mathrm{C} \quad \mathrm{Sb}_{8} \mathrm{O}_{11} \mathrm{Cl}_{2}\left(\mathrm{H}_{2} \mathrm{O}\right)_{6} \rightarrow \mathrm{Sb}_{8} \mathrm{O}_{11} \mathrm{Cl}_{2}\left(\mathrm{H}_{2} \mathrm{O}\right)_{3} \\
140-400{ }^{\circ} \mathrm{C} \quad \mathrm{Sb}_{8} \mathrm{O}_{11} \mathrm{Cl}_{2}\left(\mathrm{H}_{2} \mathrm{O}\right)_{3} \rightarrow \mathrm{Sb}_{8} \mathrm{O}_{11} \mathrm{Cl}_{2} \\
400-550{ }^{\circ} \mathrm{C} \quad \mathrm{Sb}_{8} \mathrm{O}_{11} \mathrm{Cl}_{2} \rightarrow \mathrm{Sb}_{2} \mathrm{O}_{3} \text { (senarmontite) }
\end{gathered}
$$

Fig. 3 depicts the XRD patterns of the $\mathrm{Sb}_{x} \mathrm{O}_{y} \mathrm{Cl}_{z} /$ TiONT composites synthesized at $\mathrm{pH}=1,4$ and 8 over pristine TiONT (a), and the samples calcined at $100{ }^{\circ} \mathrm{C}$ (b), $200{ }^{\circ} \mathrm{C}$ (c), $300{ }^{\circ} \mathrm{C}(\mathrm{d})$, and $400{ }^{\circ} \mathrm{C}(\mathrm{d})$ for $1 \mathrm{~h}$.

The non-heat-treated TiONT sample exhibits the characteristic reflections of the layered trititanate phase at $2 \Theta=9.3^{\circ}$; $24.4^{\circ} ; 25.5^{\circ} ; 27.8^{\circ}$ and $48.5^{\circ} .^{21,23}$ The XRD patterns of the composites prepared at $\mathrm{pH}=4$ and 8 suggest low crystallinity anatase along with some remaining trititanate phase, as evidenced by the asymmetric reflection at $24.4^{\circ}$. The composite prepared at $\mathrm{pH}=8$ is a ternary phase composed of trititanate, anatase and orthorhombic valentinite $\mathrm{Sb}_{2} \mathrm{O}_{3}$ 

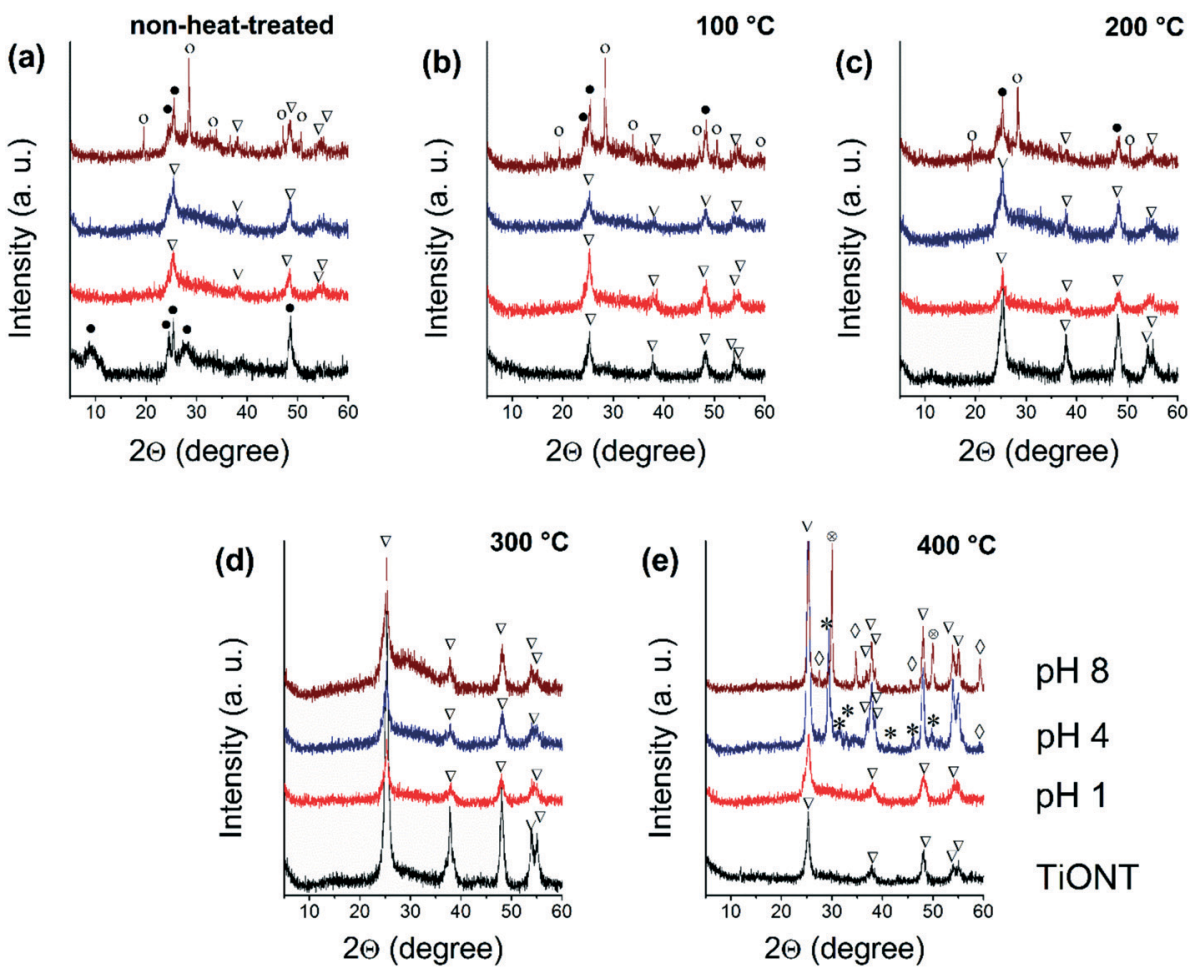

Fig. 3 XRD patterns of the as-prepared (a) and heat-treated TiONT composites calcined at $100{ }^{\circ} \mathrm{C}$ (b), $200{ }^{\circ} \mathrm{C}$ (c), $300{ }^{\circ} \mathrm{C}$ (d), and $400{ }^{\circ} \mathrm{C}$ (e). Reflections assigned to the protonated trititanate phase are marked by "•", while those characteristic of anatase $\mathrm{TiO}_{2}$ are marked by " $\mathrm{\nabla}$ ". Peaks identified by the symbols "*", "O", " $\diamond$ " and " $\otimes$ " belong to $\mathrm{Sb}_{8} \mathrm{O}_{11} \mathrm{Cl}_{2}$, valentinite $\mathrm{Sb}_{2} \mathrm{O}_{3}$, senarmontite $\mathrm{Sb}_{2} \mathrm{O}_{3}$, and cervantite $\mathrm{Sb}_{2} \mathrm{O}_{4}$, respectively.

(JCPDS: 11-0689). No indication of the antimony precursor can be found in the patterns because it was in an amorphous form in the system.

After $1 \mathrm{~h}$ calcination at 100 and $200{ }^{\circ} \mathrm{C}$, the as-prepared trititanate as well as the $\mathrm{pH} 1$ and $\mathrm{pH} 4$ composites completely transformed into anatase with a lower and a somewhat higher crystallinity degree, respectively. The $\mathrm{pH}$ 8 composite contains a trititanate phase and valentinite seems to stabilize the trititanate structure in both cases. After heat treatment at $300{ }^{\circ} \mathrm{C}$, all samples show anatase $\mathrm{TiO}_{2}$ reflections. The baseline between $2 \theta=26^{\circ}$ and $35^{\circ}$ is elevated in the patterns of the composites. This broad feature is again characteristic of the amorphous phase. This effect increases with $\mathrm{pH}$, along with the disappearance of the valentinite reflection at $28.3^{\circ}$. This seems to be a transitional state between valentinite and other SbOCl phases. At $400{ }^{\circ} \mathrm{C}$, the as-prepared TiONT formed highly crystalline anatase. In the $\mathrm{pH} 4$ composite, monoclinic $\mathrm{Sb}_{8} \mathrm{O}_{11} \mathrm{Cl}_{2}$ (JCPDS: 77-1183) and some cubic senarmontite $\mathrm{Sb}_{2} \mathrm{O}_{3}$ (JCPDS: 050534) can be found. In the $\mathrm{pH} 8$ composite, valentinite transformed into cubic senarmontite $\mathrm{Sb}_{2} \mathrm{O}_{3}$ (JCPDS: 050534) and orthorhombic cervantite $\mathrm{Sb}_{2} \mathrm{O}_{4}$ (JCPDS: 11-0694) on the surface of the titania. The $\beta-\mathrm{Sb}_{2} \mathrm{O}_{3}$ structure can turn into amorphous antimony oxide before it recrystallizes into senarmontite $\left(\mathrm{a}-\mathrm{Sb}_{2} \mathrm{O}_{3}\right)$. In the absence of a support (e.g., titanate or $\mathrm{TiO}_{2}$ ), this phase transition takes place at lower temperatures $\left(300-400{ }^{\circ} \mathrm{C}\right)$ instead of $\sim 445{ }^{\circ} \mathrm{C} .{ }^{37} \mathrm{TiO}_{2}$ is a good example that demonstrates the role of the support's surface in antimony oxide formation, since trivalent $\mathrm{Sb}$ in $\mathrm{Sb}_{2} \mathrm{O}_{3}$ can be oxidized to $\mathrm{Sb}(\mathrm{v})$ antimony oxide $\left(\mathrm{Sb}_{2} \mathrm{O}_{5}\right)$, as reported earlier. ${ }^{38}$ Although XRD patterns do not allow the direct identification of antimony oxychloride or antimony oxide below $400{ }^{\circ} \mathrm{C}$ in this supported system, the literature data indicate that the formation of $\mathrm{Sb}_{4} \mathrm{O}_{5} \mathrm{Cl}_{2}$ is favored at $\mathrm{pH}=1$, while $\mathrm{Sb}_{8} \mathrm{O}_{11} \mathrm{Cl}_{2}\left(\mathrm{H}_{2} \mathrm{O}\right)$ and/or $\mathrm{Sb}_{8} \mathrm{O}_{11} \mathrm{Cl}_{2}$ are preferred at $\mathrm{pH}=4 .{ }^{12,20}$

The XRD patterns of the composites formed on anatase $\mathrm{TiO}_{2}$ are shown in Fig. S5. $\dagger$ The commercial $\mathrm{TiO}_{2}$ exhibits the same crystal structure at all temperatures (anatase, JCPDS: 21-1272). $\quad \mathrm{Sb}_{8} \mathrm{O}_{11} \mathrm{Cl}_{2}\left(\mathrm{H}_{2} \mathrm{O}\right)_{6}$ (orthorhombic, JCPDS: 77-1584) formed on the non-heat-treated samples in both the $\mathrm{pH}=1$ and the $\mathrm{pH}=4$ cases. Reflections in the profile of the $\mathrm{pH}=8$ sample indicate the presence of valentinite and senarmontite $\mathrm{Sb}_{2} \mathrm{O}_{3}$ as well as anatase $\mathrm{TiO}_{2}$. After calcination at $100{ }^{\circ} \mathrm{C}$, no change was observed, but at $200{ }^{\circ} \mathrm{C}$ the antimony oxychloride hydrate partially (and later, completely) lost its crystal water in the $\mathrm{pH}=1$ and $\mathrm{pH}=4$ cases and transformed into $\mathrm{Sb}_{8} \mathrm{O}_{11} \mathrm{Cl}_{2}$. No changes were found in the $\mathrm{pH} 8$ composite. At $300{ }^{\circ} \mathrm{C}, \mathrm{pH}=1$ and $\mathrm{pH}=4$ oxychloride hydrates were completely converted to oxychloride. During heat treatment at $400{ }^{\circ} \mathrm{C}$, oxychlorides in composites $\mathrm{pH}=1$ and $\mathrm{pH}=4$ were converted to cervantite $\mathrm{Sb}_{2} \mathrm{O}_{4}$ and senarmontite $\mathrm{Sb}_{2} \mathrm{O}_{3}$ antimony oxides. The $\mathrm{pH}=8$ sample contained valentinite $\mathrm{Sb}_{2} \mathrm{O}_{3}$ besides the senarmontite antimony oxides. 


\subsection{Optical properties and band gap energies of the structures}

The band gap energy of semiconductors is of vital importance in photocatalysis. The system studied here was constructed from n-type semiconductors (as indicated by the slope of the Mott-Schottky plot in Fig. S12†), namely: titanate and $\mathrm{TiO}_{2}$ nanotubes and anatase $\mathrm{TiO}_{2}$ particles in direct contact with various $\mathrm{Sb}_{x} \mathrm{O}_{y} \mathrm{Cl}_{z}$ nanoparticles. The optical properties and band gaps of the pristine materials and composites were determined from the diffuse reflectance UV-vis spectra. The spectra of the TiONT and $\mathrm{TiO}_{2}$ based composites are shown in the absorbance and Kubelka-Munk formalisms in Fig. S6-S9, $\uparrow$ respectively. Both sets of spectra show optical absorption mainly in the UV regime in all the samples, with an elevated baseline absorption in the visible range for the TiONT-based composites. This feature likely originates from the $\mathrm{Sb}_{x} \mathrm{O}_{y} \mathrm{Cl}_{z}$ particles and the vacancy states of the support. It gave a yellowish color to the materials. Furthermore, the absorption edge in the spectra after $\mathrm{Sb}_{x} \mathrm{O}_{y} \mathrm{Cl}_{z}$ decoration became less steep, indicating a band gap narrowing effect in the structure. The optical behavior of all the $\mathrm{TiO}_{2}$ composites is basically the same (Fig. S8 and S9†); their characteristics are unchanged except for a mild elevation of the baseline in the visible region. The corresponding band gaps were calculated from the Kubelka-Munk plots, ${ }^{39}$ suggesting indirect band gaps in all composites (earlier in $\mathrm{Sb}_{4} \mathrm{O}_{5} \mathrm{Cl}_{2}$ a direct band gap was suggested ${ }^{16}$ ). Although the band gap in the anatase composites remains constant $(3.26 \mathrm{eV})$, nanoparticle decoration in TiONT composites affects these values, as summarized in Table $\mathrm{S} 1 . \dagger$

Trititanate nanostructures are wide band gap semiconductors with band gap energies between 3.30 and $3.40 \mathrm{eV}$. The value of $3.36 \mathrm{eV}(\sim 370 \mathrm{~nm})$ obtained here can thus be considered as a typical value. ${ }^{21,40}$ Upon calcination, TiONTs transform into 1D anatase along with the narrowing of the band gap to $\sim 3.20 \mathrm{eV}$. The decoration of the pristine nanotubes with nanoparticles decreased the energy required for charge carrier generation to as low as $3.05 \pm 0.02 \mathrm{eV}$ in the $\mathrm{pH} 1$ composite. Nevertheless, the band gap energy remained in the 3.00-3.10 eV region for all the samples, thus confirming the qualitative findings from the UV-vis spectra in Fig. S6. $\dagger$ As absorption at $400 \mathrm{~nm}$ means an artificial borderline between UV and VIS with a corresponding band gap of $3.10 \mathrm{eV}$, the values summarized in Table $\mathrm{S} 1 \uparrow$ imply that our photocatalytic system is mainly active in the UV regime. The origin of the band gap narrowing is yet unclear, although it is likely connected to the structural and compositional variation during heat treatment. A study on nanosized $\mathrm{BiOX}(\mathrm{X}=\mathrm{Cl}, \mathrm{Br}, \mathrm{I})$ showed particle size dependent band gaps in this semiconductor family, ${ }^{41}$ and this effect probably occurs in the structures studied here as well.

\subsection{Photocatalytic tests}

The decolorization of water soluble organic dyes (in particular, of methyl orange (MO) dye) is one of the universally ac- cepted quasi-standard photocatalytic tests. Therefore, the photocatalytic activity of the samples was tested in this reaction. The photocatalytic curves (variation of the MO concentration with the irradiation time) for the TiONT composites are depicted in Fig. $\mathrm{S} 10 \dagger$ in a linearized representation: $\ln \left(C_{0}\right)$ $C$ ) is plotted against time, where $C$ and $C_{0}$ are the apparent and initial dye concentrations, respectively. The lines are linear fits to the data according to the $\ln \left(C_{0} / C\right)=k t$ first-order rate equation, where $k$ is the apparent rate constant. Although the pristine TiONT could not change the MO concentration in the experiment, decoration with $\mathrm{Sb}_{x} \mathrm{O}_{y} \mathrm{Cl}_{z}$ nanoparticles at $\mathrm{pH}=1$ and 4 enhanced the activity of the system. The particles synthesized at $\mathrm{pH}=8$, however, do not show any significant effect. Their activities decreased after calcination, with the pH 1 sample preserving most of its activity. Interestingly, anatase $\mathrm{TiO}_{2}$ based composites showed very low activities: after the first 5 minutes of each experiment, the decolorization efficiency declined even more significantly. From that point on, the decolorization reaction did not follow a first-order kinetic anymore, as shown in Fig. S11.† Here, only the first part of the experiments was evaluated. The apparent rate constants for all the samples are summarized in Tables $\mathrm{S} 2$ and $\mathrm{S} 3 \uparrow$ for the TiONT and $\mathrm{TiO}_{2}$ based composites, respectively, and are also plotted in Fig. 4 for comparison. In Table $\mathrm{S} 4 \uparrow$ the photocatalytic MO decolorization activities of various antimony and bismuth oxyhalogenide containing photocatalysts are summarized. It should be noted here that direct comparison between different solid catalysts based on reaction rates or the decomposed amount of material, even in the same decolorization reaction, is not possible. ${ }^{42}$ Recently, considerable efforts have been made in the standardization of photocatalytic experiments, which in turn would ensure effective benchmarking of photocatalysts. ${ }^{43}$

The pristine titanate nanotubes in Fig. 4a do not exhibit any activity in the test reaction even after heat treatment up to $400{ }^{\circ} \mathrm{C}$. On the other hand, the nanoparticle decorated nanotubes were found to be active in the dye decolorization tests. The composites synthesized at $\mathrm{pH}=1$ and 4 had the highest activity among all the catalysts investigated. After calcination, the $\mathrm{pH} 1$ composite remained active up to $300{ }^{\circ} \mathrm{C}$, while the activity of $\mathrm{pH} 4$ declined monotonously. The $\mathrm{pH}$ 8 sample reached its peak activity at $100{ }^{\circ} \mathrm{C}$, however, the corresponding rate constant remained low in the whole temperature range studied. All the composites show low activity at $400{ }^{\circ} \mathrm{C}$, along with the emergence of the anatase phase. The $\mathrm{TiO}_{2}$ based composites in Fig. $4 \mathrm{~b}$ show very low (i.e., one order of magnitude lower) activity in each experiment compared to the TiONT based composites. Moreover, their behavior was independent of any subsequent heat treatment applied to the pristine samples. The magnified inset panel highlights the activity drop after calcination at $400{ }^{\circ} \mathrm{C}$. Since these samples were based on commercial anatase, the decline in activity cannot stem from the appearance of the anatase crystal phase, and therefore, its origin is unclear yet. We found that the $\mathrm{Sb}_{x} \mathrm{O}_{y} \mathrm{Cl}_{z}$ /TiONT sample synthesized at $\mathrm{pH}=1$ is the most active in a broad temperature range. 

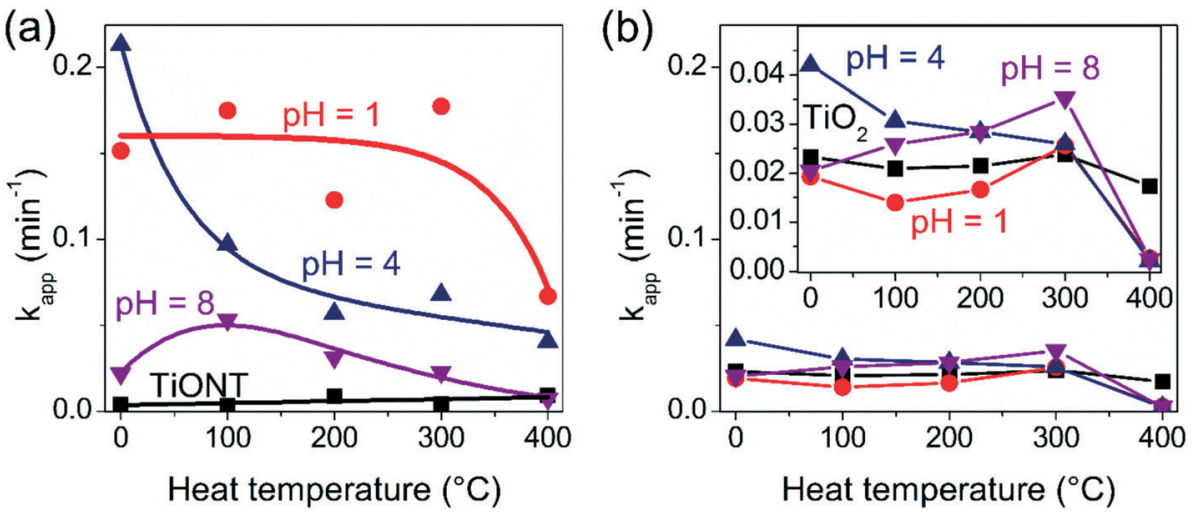

Fig. 4 Variation of the apparent reaction rate constants in methyl orange decolorization with the calcination temperature in $\mathrm{TiONT}^{-}(\mathrm{a})$, and $\mathrm{TiO}_{2}-$ based (b) $\mathrm{Sb}_{x} \mathrm{O}_{y} \mathrm{Cl}_{z}$ composites. Lines connecting the data points serve as a guide for the eyes.

\subsection{Band structure and photocatalysis mechanism}

Constructing a composite photocatalyst can be favorable as hybrid structures steer charge kinetics, and heterojunctions promote the separation of photogenerated charge carriers. This hinders charge recombination and prolongs the lifetime of electron-hole pairs. ${ }^{5}$ If both constituents of a composite can be excited by the incoming irradiation, then electronhole pairs are generated in both materials. The electrons are then transported from the component with a higher conduction band to that with a lower one, while the holes are removed from the lower valence band material to that with a higher valence band edge. This type of excitation scheme usually happens under $\mathrm{UV}^{27-30}$ or UV-vis irradiation. The latter is also the case in this study. Fig. 5 shows the band diagram of the TiONT based composites, and the band alignment before and after heterojunction formation.

Band edge energies for different antimony oxychlorides are almost completely missing from the literature. Data for certain $\mathrm{Sb}_{4} \mathrm{O}_{5} \mathrm{Cl}_{2}$ compositions have only been published recently. $^{16}$ Therefore, Mott-Schottky analysis on our $\mathrm{pH} 1$ composite $\left(\mathrm{Sb}_{8} \mathrm{O}_{11} \mathrm{Cl}_{2} / \mathrm{TiONT}\right)$ was performed, and the result is shown in Fig. S12. $\dagger$ The sample is an n-type semiconductor with a conduction band edge of $-0.42 \mathrm{~V}(\mathrm{NHE})(-4.02 \mathrm{eV}$ on the vacuum scale). Taking the average band gap of all the composites $(3.08 \pm 0.06 \mathrm{eV}$ from Table $\mathrm{S} 1 \dagger)$ into account, the valence band edge of $+2.66 \mathrm{~V}(\mathrm{NHE})(-7.10 \mathrm{eV}$ on the vacuum scale) was obtained. The values for TiONT and methyl orange were extracted from the theoretical work of $\mathrm{Xu}$ et $a l^{44}$ and Saleh et al., ${ }^{45}$ respectively. The prepared composites are, therefore, $\mathrm{n}-\mathrm{n}$ heterojunctions, in which both parts can be excited by the applied UV/vis irradiation. Further electrons can be present in the system as the organic dye in the solution can sensitize the structure. After the excitation of the conjugated $\pi$ electron system of methyl orange, the excited dye can transfer electrons to the conduction band of the photocatalyst. This is a widely known phenomenon, ${ }^{46}$ which takes place in dye decolorization experiments under visible light irradiation. ${ }^{47}$ The structure is a Type II (staggered) heterostructure $^{5}$ with inversed band positions compared to that of the $\mathrm{BiOCl} / \mathrm{TiO}_{x}$ composites. In the latter, BiOCl band edges were found at more negative potentials ( $v s$. NHE) than those of the $\mathrm{TiO}_{x}$ support. ${ }^{48}$ This means an opposite charge transport between the heterojunction parts. After band alignment, photogenerated electrons flow towards the conduction band of TiONT, while holes are transported to the valence

\section{(a)}
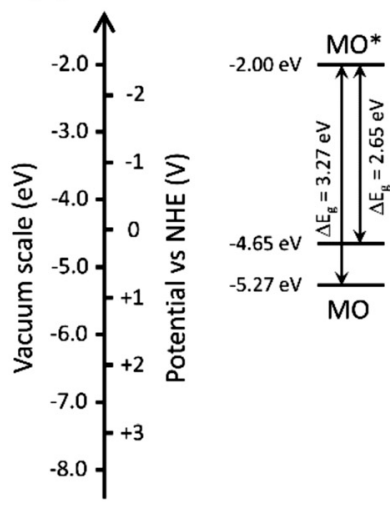

Before contact

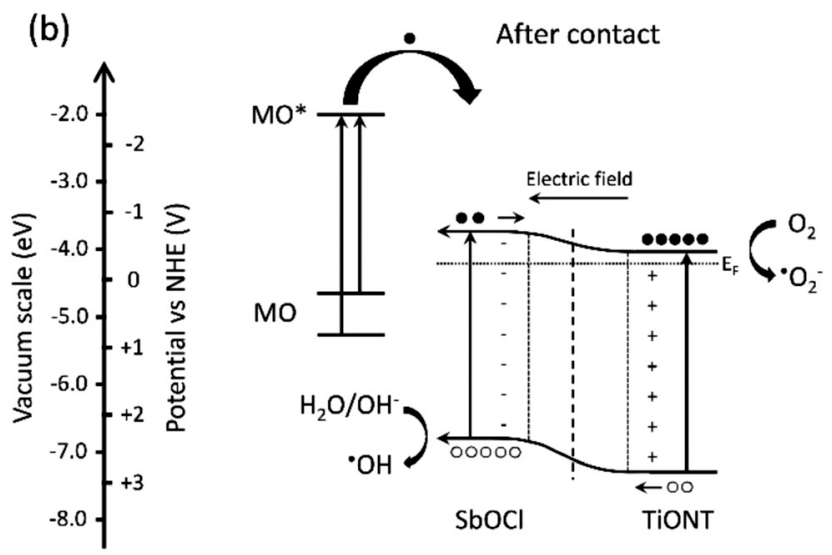

Fig. 5 Schematic illustration of the band structure and alignment before (a) and after contact (b) of the $\mathrm{Sb}_{x} \mathrm{O}_{y} \mathrm{Cl}_{z}$ nanoparticles and TiONT support. Transport of the generated charge carriers and a possible mechanism of the photocatalytic dye degradation are also depicted. 
band of the SbOCl nanoparticles due to the favorable band edge positions. Charge separation is further promoted by the development of an inner electric field at the junction of the $\mathrm{Sb}_{x} \mathrm{O}_{y} \mathrm{Cl}_{z}$ nanoparticles and the TiONT support. Although our composites are $\mathbf{n}-\mathbf{n}$ type heterostructures and the difference between work functions is considerably smaller in them than in a $\mathrm{p}-\mathrm{n}$ structure, the developing electric field can still induce charge redistribution in the structure. ${ }^{5}$ This hinders the recombination of charge carriers and thus results in a prolonged carrier lifetime. The longer charge carrier lifetime and the sensitized conduction band then result in the enhanced generation of reactive species at the photocatalyst's surface. This implies an improved photocatalytic activity.

\section{Conclusions}

While bismuth oxyhalides are popular photocatalysts in the literature today, studies on the photocatalytic activity of antimony oxyhalides are scarce. Here, we reported the successful decoration of different titanium oxide nanostructures with $\mathrm{Sb}_{x} \mathrm{O}_{y} \mathrm{Cl}_{z}$ nanoparticles for the first time ever. The size and stoichiometry of the product could be controlled by the $\mathrm{pH}$ of the synthesis medium. Subsequent calcination could further transform the as-prepared titanate and $\mathrm{Sb}_{x} \mathrm{O}_{y} \mathrm{Cl}_{z}$ structures. While $\mathrm{Sb}_{x} \mathrm{O}_{y} \mathrm{Cl}_{z} /$ TiONT composites formed easily, anatase $\mathrm{TiO}_{2}$ could not facilitate antimony oxychloride nanoparticle formation. The TiONT based composites exhibited appreciable activity in the generally accepted organic dye (methyl orange) photocatalytic decolorization experiments. $\mathrm{Sb}_{x} \mathrm{O}_{y} \mathrm{Cl}_{z} /$ TiONT synthesized at $\mathrm{pH}=1$ was the most active photocatalyst in a broad temperature range due to the formation of heterojunctions between the $\mathrm{Sb}_{x} \mathrm{O}_{y} \mathrm{Cl}_{z}$ and TiONT components, as clearly demonstrated by our experiments.

\section{Acknowledgements}

The financial support from the Hungarian Research Development and Innovation Office through grants GINOP-2.3.2-152016-00013, NKFIH OTKA K 112531 and $\mathrm{K} 120115$ is acknowledged.

\section{References}

1 H. Kazuhito, I. Hiroshi and F. Akira, Jpn. J. Appl. Phys., 2005, 44, 8269.

2 M. Hodos, E. Horváth, H. Haspel, Á. Kukovecz, Z. Kónya and I. Kiricsi, Chem. Phys. Lett., 2004, 399, 512-515.

3 R. Asahi, T. Morikawa, T. Ohwaki, K. Aoki and Y. Taga, Science, 2001, 293, 269-271.

4 W. Qin, D. Zhang, D. Zhao, L. Wang and K. Zheng, Chem. Commun., 2010, 46, 2304-2306.

5 S. Bai, J. Jiang, Q. Zhang and Y. Xiong, Chem. Soc. Rev., 2015, 44, 2893-2939.

6 S. J. Moniz, S. A. Shevlin, D. J. Martin, Z. Guo and J. Tang, Energy Environ. Sci., 2015, 8, 731-759.

7 W. W. Lee, C. Lu, C. Chuang, Y. Chen, J. Fu, C. Siao and C. Chen, RSC Adv., 2015, 5, 23450-23463.
8 K. Zhang, C. Liu, F. Huang, C. Zheng and W. Wang, Appl. Catal., B, 2006, 68, 125-129.

9 J. Di, J. Xia, M. Ji, S. Yin, H. Li, H. Xu, Q. Zhang and H. Li, J. Mater. Chem. A, 2015, 3, 15108-15118.

10 Y. Peng, D. Wang, H. Zhou and A. Xu, CrystEngComm, 2015, 17, 3845-3851.

11 C. Yang, F. Li and T. Li, CrystEngComm, 2015, 17, 7676-7683.

12 J. Zhou, H. Zhao, L. Li, M. Tian, J. Han, L. Zhang and L. Guo, J. Nanosci. Nanotechnol., 2011, 11, 8504-8509.

13 C. Särnstrand, Acta Crystallogr., Sect. B: Struct. Crystallogr. Cryst. Chem., 1978, 34, 2402-2407.

14 J. Shu, R. Ma, L. Shao, M. Shui, L. Hou, K. Wu, Y. Chen, D. Wang, Y. Liang and Y. Ren, RSC Adv., 2013, 3, 372-376.

15 P. Li, J. Shu, L. Shao, X. Lin, K. Wu, M. Shui, D. Wang, N. Long and Y. Ren, J. Electroanal. Chem., 2014, 731, 128-132.

16 L. Yang, J. Huang, L. Cao, L. Shi, Q. Yu, X. Kong and Y. Jie, Sci. Rep., 2016, 6, 27765.

17 Q. Jiang, X. Yuan, H. Wang, X. Chen, S. Gu, Y. Liu, Z. Wu and G. Zeng, RSC Adv., 2015, 5, 53019-53024.

18 Y. Liu, X. Yuan, H. Wang, X. Chen, S. Gu, Q. Jiang, Z. Wu, L. Jiang, Y. Wu and G. Zeng, Catal. Commun., 2015, 70, 17-20.

19 J. Tang, Y. Wang, Z. Jiao and M. Wu, Mater. Lett., 2009, 63, 1481-1484.

20 X. Y. Chen, H. S. Huh and S. W. Lee, J. Solid State Chem., 2008, 181, 2127-2132.

21 D. V. Bavykin and F. C. Walsh, Titanate and titania nanotubes: synthesis, properties and applications, Royal Society of Chemistry, 2010.

22 D. Madarász, I. Szenti, A. Sápi, J. Halász, Á. Kukovecz and Z. Kónya, Chem. Phys. Lett., 2014, 591, 161-165.

23 G. Pótári, D. Madarász, L. Nagy, B. László, A. Sápi, A. Oszkó, A. Kukovecz, A. Erdohelyi, Z. Kónya and J. Kiss, Langmuir, 2013, 29, 3061-3072.

24 B. Buchholcz, H. Haspel, Á. Kukovecz and Z. Kónya, CrystEngComm, 2014, 16, 7486-7492.

25 Y. I. Choi, K. H. Jeon, H. S. Kim, J. H. Lee, S. J. Park, J. E. Roh, M. M. Khan and Y. Sohn, Sep. Purif. Technol., 2016, 160, 28-42.

26 W. Li, Y. Tian, H. Li, C. Zhao, B. Zhang, H. Zhang, W. Geng and Q. Zhang, Appl. Catal., A, 2016, 516, 81-89.

27 F. Duo, Y. Wang, C. Fan, X. Mao, X. Zhang, Y. Wang and J. Liu, Mater. Charact., 2015, 99, 8-16.

28 W. Fan, X. Yu, S. Song, H. Bai, C. Zhang, D. Yan, C. Liu, Q. Wang and W. Shi, CrystEngComm, 2014, 16, 820-825.

29 Z. Liu, X. Xu, J. Fang, X. Zhu and B. Li, Water, Air, Soil Pollut., 2012, 223, 2783-2798.

30 D. Sun, J. Li, L. He, B. Zhao, T. Wang, R. Li, S. Yin, Z. Feng and T. Sato, CrystEngComm, 2014, 16, 7564-7574.

31 J. Song, Q. Fan, W. Zhu, R. Wang and Z. Dong, Mater. Lett., 2016, 165, 14-18.

32 K. Wang, C. Shao, X. Li, F. Miao, N. Lu and Y. Liu, Materials, 2016, 9, 90. 
33 T. Kasuga, M. Hiramatsu, A. Hoson, T. Sekino and K. Niihara, Langmuir, 1998, 14, 3160-3163.

34 D. A. Hanaor and C. C. Sorrell, J. Mater. Sci., 2011, 46, 855-874.

35 A. Rónavári, B. Buchholcz, Á. Kukovecz and Z. Kónya, J. Mol. Struct., 2013, 1044, 104-108.

36 W. Yang, M. Tang and S. Jin, Trans. Nonferrous Met. Soc. China, 2002, 12, 156-159.

37 R. Orman and D. Holland, J. Solid State Chem., 2007, 180, 2587-2596.

38 B. Pillep, P. Behrens, U. Schubert, J. Spengler and H. Knözinger, J. Phys. Chem. B, 1999, 103, 9595-9603.

39 P. Kubelka and F. Munk, Z. Tech. Phys., 1931, 12.

40 P. Pusztai, R. Puskas, E. Varga, A. Erdőhelyi, A. Kukovecz, Z. Konya and J. Kiss, Phys. Chem. Chem. Phys., 2014, 16, 26786-26797.
41 L. Chen, S. Yin, R. Huang, Y. Zhou, S. Luo and C. Au, Catal. Commun., 2012, 23, 54-57.

42 H. Kish and D. Bahnemann, J. Phys. Chem. Lett., 2015, 6, 1907-1910.

43 M. Qureshi and K. Takanabe, Chem. Mater., 2014, 29, 158-167.

44 X. Xu, X. Ding, Q. Chen and L. Peng, Phys. Rev. B: Condens. Matter Mater. Phys., 2007, 75, 035423.

45 T. A. Saleh, A. A. Al-Saadi and V. K. Gupta, J. Mol. Liq., 2014, 191, 85-91.

46 J. H. Yum, P. Chen, M. Grätzel and M. K. Nazeeruddin, ChemSusChem, 2008, 1, 699-707.

47 S. Bae, S. Kim, S. Lee and W. Choi, Catal. Today, 2014, 224, 21-28.

48 J. Hu, W. Fan, W. Ye, C. Huang and X. Qiu, Appl. Catal., B, 2014, 158, 182-189. 